If the number of young people leaving school and college is much larger in recent years than at the beginning of the century, it would seem that this is less marked in Switzerland than in certain other countries. For example, it is pointed out that, in 1930-31, per 100,000 of population, Germany had 63 Abiturienten (holders of school-leaving certificates or equivalent) whereas Switzerland had only 34. Japan and Rumania in 1934 had more than six times as many with academic training as in 1913. In the same period those of Holland increased by 146 per cent, of France 112 per cent, of Great Britain 83 per cent, and of Switzerland 59 per cent. According to Dr. Erb, the most disturbing aspect of this increase in quantity is the serious decline in quality: he thinks the standard, however measured, is definitely lower. The real problem, therefore, is not necessarily 'too many', but 'too many of the wrong type'. Mediocrity is said to be very noticeable in the universities and secondary schools. There are far too many Brodstudenten, or those who concentrate too closely on the vocational side to the neglect of the broader cultural and intellectual aspect. They specialize too soon and aim at passing through the technical schools as quickly as possible. The sole business of education, in their view, is to enable one to earn a living in some narrowly specialized sphere. We are faced again with the dangers of specialization, which have been debated ad nauseam in recent years.

$D^{r}$. Erb may have put his finger on one of the main sources of the trouble when he admits that schoolbuilding accommodation and number of teachers have not kept pace with the increased number of entrants. Teaching has become less individualistic than ever, and tends to savour of mass-production methods. It is difficult, of course, to be precise on this matter of quality; but both in the universities and in industry there are complaints that, despite the large increase in number of those with academic training, there is serious lack of the right type for the needs of industry and trade. If sufficient school space is wanting; if there are too few teachers and these are underpaid, with inadequate status and insufficient knowledge of the needs of business and industry, then the quality of the students must necessarily suffer. Certain it is that many of them show signs of hurried and inadequate training, both of mind and character-especially the latter: they are incapable of adapting themselves readily to the realities of life, from which they expect too much.

Although Dr. Erb complains that educational, or at least academic, statistics are not so good as they might be, and those which are available are not intelligently used, he thinks there is little doubt that the number of entrants to schools and universities tends to increase considerably in periods of industrial prosperity; but by the time these new entrants have finished their scholastic career, the boom period has been succeeded by depression, and they are condemned to unemployment; so much harder to bear in proportion to their academic qualifications. This is one of the tragedies of unemployment, raising larger issues than can be dealt with here; nevertheless, it must be remembered that, as already indicated, chances of employment for those with academic training even in lean times-would be increased if they were more adequately or properly trained.

Reference is made also to the impact of social conditions and changes on the relative numbers of students at secondary schools and universities. The rights of man and consequent social philosophy of the nineteenth century led to the emancipation of the lower classes and of women, and to increasing demands for improved social status and better education. Dr. Erb considers that, in Switzerland, the exaggerated importance imputed to academic learning of the more showy or superficial type was particularly marked, and was closely associated with the growing social prejudice for black-coated respectability. Those who had not themselves attained to this status were anxious and determined that their children should do so ; and this delusion, says Dr. Erb, will continue until it is more generally realized that the harder one studies the more certainly will he miss the road to wealth. This may be often true, but scarcely attains the dignity of a general proposition; and in any event strikes a slightly discordant note in its present context.

Among remedial measures suggested are a more careful selection of candidates for the school-leaving examinations, and greater attention to the importance of test or observation periods rather than exclusive concentration on examination results. In other words, the examination system is again under criticism, as is frequently the case to-day. Dr. Erb is strongly of opinion that the path to the university should be more strictly reserved to those above the general average who can best profit by university training. Not only should the school-leaving examinations (Maturitätsschule and Auslese) be considerably tightened up and revised, but also they should be supplemented by a system of character tests and observation periods, so that the real abilities of the student, not necessarily brought out by the usual examination, could be much more elearly and thoroughly ascertained. The examinations themselves should not usually be made more difficult in the sense of book knowledge - they are already too overloaded-but rather should include tests of character and personality not generally provided for in the examination papers.

\section{CORRELATION OF THIXOTROPIC SETTING WITH DENSITY IN SILVER AMALGAMS}

\author{
By Dr. D. R. HUDSON \\ Heriot-Watt College, Edinburgh
}

CILVER and mercury form, by peritectic reactions at $276^{\circ}$ and $127^{\circ} \mathrm{C}$. respectively, intermetallic compounds represented very nearly by the formulæ $\mathrm{AgHg}$ and $\mathrm{Ag}_{3} \mathrm{Hg}_{4}$. They exist in space lattices of the close-packed hexagonal type with $a=2 \cdot 987 \mathrm{~A}$., $c / a=1 \cdot 62$, and the body-centred cubic type with $a=10-10 \cdot 1 \mathrm{~A}$., respectively ; the latter resembles the well-known $\gamma$-brass structure, but is not identical with it. In synthesized amalgams the range of stability of both species is small, probably not exceeding $\pm \frac{1}{2}$ per cent. $\mathrm{Ag}_{3} \mathrm{Hg}_{4}$ exists as native amalgam (argental or landsbergite) often in very well-formed crystals in the cubic system, corresponding closely in composition to the artificial product; AgHg has not, so far, been reported in minerals, and Heide has suggested that this species does not occur native. Further, $\mathrm{Ag}_{3} \mathrm{Hg}_{4}-\mathrm{known}$ already to the alchemists as Arbor Dianae-can be obtained chemically by displacement of ions of either metal in solution by the action of the other. This is in accordance with the fact that the two standard 
electrode potentials are almost identical : $0.799 \mathrm{v}$. for $\mathrm{Hg}: \mathrm{Hg}_{2} \cdot$ and $0.798 \mathrm{v}$. for $\mathrm{Ag}: \mathrm{Ag} \cdot$ at $25^{\circ} \mathrm{C}$. In the hardening of plastic dental amalgams, $\mathrm{Ag}_{3} \mathrm{Hg}_{4}$ is formed by the reaction

$$
\underset{\text { flings }}{\mathrm{Ag}_{3} \mathrm{Sn}}+\underset{\text { liquid }}{\mathrm{Hg}} \rightleftarrows \underset{\text { dendrites }}{\mathrm{Ag}_{3} \mathrm{Hg}_{4}}+\underset{\begin{array}{c}
\text { solid solution } \\
\text { (Black, Troiano) }
\end{array}}{\mathrm{Sn}(\mathrm{Hg})}
$$

Densities of heterogeneous silver amalgams. The variation of density with composition has been deter. mined for the heterogeneous range. Although the solubility of silver in mercury is small--only about 0.03 per cent at room temperature-they are quite fluid up to about 8 per cent. Between about 8 per cent and about 20 per cent silver, they are plastic on formation but 'set' on standing overnight; above 20 per cent they resemble hard 'Plasticine' rather than a heterogeneous mass, becoming gradually harder as the composition of the solid amalgam is approached. This was found to be 27.43 and 27.72 per cent in two separate experiments, by expulsion of the liquid phase (argentiferous mercury) under severe compression. By very careful handling of the set amalgams, it was found possible to use Archimedes' method down to about $13 \frac{1}{2}$ per cent silver; below this a special midget ( $2 \frac{1}{2} \mathrm{ml}$.) specific gravity bottle was used with success. The results are in fair agreement with the older determinations of Mrey (1905), but are more consistent among themselves and probably rather more accurate than these; the very erratic values reported by Joule (1863) and Duczko (1935) were not confirmed. The density/composition curve shows small but distinct peaks at about 15 and 28 per cent, about $13 \cdot 61$ and $13 \cdot 60$ respectively, with minima at about 13 and 25 per cent, that is, $13 \cdot 47$ and $13 \cdot 37$. Between these points the curve is made up of straight lines and the density is invariably above that calculated for a conglomerate by summation of volumes. The silver content (at the mercury boundary) lies about midway between $\left(\mathrm{Ag}_{3} \mathrm{Hg}_{4}\right)_{4}$ proposed by Weryha (28.74 per cent), and $\left(\mathrm{Ag}_{2} \mathrm{Hg}_{3}\right)_{10}$ proposed by Berman and Harcourt (26.4 per cent), but a Hume-Rothery constitution $\left(\mathrm{Ag}_{5} \mathrm{Hg}_{8}\right)_{4}$ is definitely excluded by present results as well as by $X$-radiological and metallographic data.

Setting and Thixotropy. The amalgams set like plaster of Paris when they contain more than 8 per cent silver, but the process is very different, being completely and repeatedly reversible by pressure alone. During setting, the hardness increases ; above 20 per cent one can obtain a robust mass which becomes quite plastic on kneading. This process is thixotropic, being due to the formation of a welldefined reseau of acicular crystals, which is quickly degraded under local pressure. Surplus mercury is held in this spongy structure as a result of its high surface tension, and in the mercury-rich amalgams may be seen to liquate out, leaving the dry réseau intact. It is rare to find thixotropy displayed so perfectly as in these amalgams.

Effect of setting on density. With the incidence of setting there is also a fall in density of $1-1 \frac{1}{2}$ per cent in a few days. In an extreme case, a 15 per cent alloy, which had stood undisturbed for more than two years, segregated into hard discrete equi-axed lumps and argentiferous mercury. Hard grinding was required to restore this to the plastic state, when its density was found to be normal and as much as 4 per cent greater. This ('pea' plus liquid) state is regarded as the ultimate limit of thixotropic setting, equivalent to complete spheroidization of cementite in steel. Two explanations are suggested.
(1) That pressure causes Murphy's peritectic reaction at $127^{\circ} \mathrm{C}$. to go leftward at room temperature. $\beta+\mathrm{Hg} \rightleftarrows \gamma$, or very nearly $3 \mathrm{AgHg}+\mathrm{Hg} \rightleftarrows \mathrm{Ag}_{3} \mathrm{Hg}_{4}$.

(2) That the reseau consists of another intermetallic species, formed on standing and restored on kneading to the $\mathrm{Ag}_{3} \mathrm{Hg}_{4}$ originally present. This species might be either the same phase $(27 \cdot 7$ per cent silver) in another space lattice with different physical properties, or a new intermetallic compound, possibly of different composition. Unfortunately, the relative proportion of jagged crystals and argentiferous mercury in the 15 per cent amalgam was not deter. mined accurately. It may be estimated to be about $1: 2$, which would give an approximate silver content of about 45 per cent, the solubility of silver in liquid mercury being very small at room temperature. One may recall Murphy's $\beta$-constituent containing about 40 per cent mercury, which we have denoted $\mathrm{AgHg}$.

Dental amalgams. The unexpectedly low density of the set structure (spongy réseau plus argentiferous mercury) accounts very happily for the paradoxical expansion of tooth stoppings too rich in silver-a sharp change in setting characteristics takes place at 25 5-26 per cent. This bugbear led to the postulation of void formation by Gray, which faute de mieux has been accepted by Troiano and Gayler. However, in the specimen mentioned, in which the thixotropy had proceeded to the extreme limit, the measured difference of 4 per cent in density would require a void volume of as much as one eighth in the 'peas'. In view of their hardness and jagged nature, this is very difficult to accept. Moreover, it is somehow repugnant to scientific intuition to believe that voids can be formed on dendritic erystallization within a mother liquor with surface energy as high as mercury. Sullivan's amalgam of precipitated copper and mercury, now discarded in dentistry, is plastic but sets hard in a few hours, and can then be rolled or hammered. On kneading or heating, the mass recovers its plasticity.

Application to other physical properties. It is formally suggested that other anomalies in the physical properties of amalgams of alkalis and other metals, for example, viscosity, surface tension, electrical conductance, may also be due to thixotropy rather than to colloid formation.

\section{A SIMPLE TECHNIQUE FOR PHOTOMICROGRAPHY}

\section{By DR. W. N. LEAK}

$T^{O}$ record of a microscopical preparation can com1 pare in value with a photograph, yet photomicrographs are often not taken so frequently as workers might wish because of the difficulty of doing the work personally or the interruption caused by sending it to a special photomicrographical department. There is, however, a simple method of obtaining excellent photomicrographs. The method depends on the fact that a camera will photograph a virtual image as easily as it will a real object. The image in a microscope is a virtual one, and if this is focused, as it normally is, at infinity, and a camera, also focused at infinity, is placed as near as possible to the ocular, so that all the light coming through the ocular enters the camera lens, a good photograph will result if the exposure is correct and the camera truly in line with the microscope tube. In actual practice this can be judged sufficiently well by eye, 